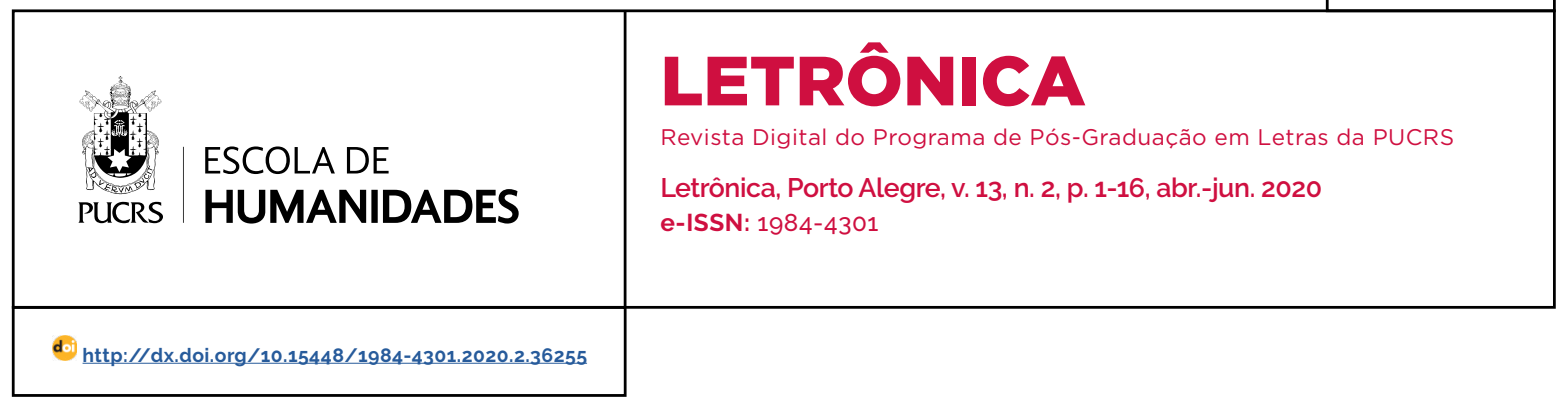

\title{
Charge com contorno intolerante: uma análise discursiva ${ }^{1}$
}

\author{
Cartoons with intolerant contours: a discursive analysis
}

\section{Tamiris Machado}

Gonçalves ${ }^{2}$

orcid.org/0000-0003-2551-0309

mtamiris@gmail.com

Recebido em: 6 nov. 2019 .

Aprovado em: 16 fev. 2020.

Publicado em: 13 ago. 2020.
Resumo: A charge é um gênero discursivo critico, no sentido de ser a apreciação de um sujeito sobre temas sociais que the circunscrevem. Assim sendo, ela pode reverberar diversos efeitos de sentido, tais como humor, ironia, afrontamento, oportunizando uma análise de linguagem em uso. O objetivo deste artigo é compreender os elementos constitutivos de uma charge de Roque Sponholz, veiculada em 2011, na mídia digital brasileira. Visa-se entender nesse ato quais recursos são mobilizados para a edificação de sentidos intolerantes; bem como quais fios dialógicos são necessários para que uma charge seja entendida como tendo contorno intolerante. Para tanto, recorre-se à perspectiva teórico-metodológica do discurso, sobretudo a postulada pelo Círculo de Bakhtin. A análise indica que a charge em questão se volta para discursos sociais intolerantes, tanto em um movimento de relação com já ditos quanto na projeção de discursos-resposta. Nesse fazer, sua arquitetônica assume sentidos de intolerância enquanto um todo discursivo que deixa ver juizos de valor.

Palavras-chave: Círculo de Bakhtin. Discurso intolerante. Construção de sentidos. Charge jornalistica.

Abstract: Cartoons are a critical speech genre, in the sense that they are one's assessment about social themes in which one is circumscribed. Therefore, cartoons may reverberate many sense effects, such as humor, irony and affront, enabling an analysis of language in use. This article's objective is to comprehend the constitutive elements of a cartoon by Roque Sponholz, published in 2011, via Brazilian digital media. It is aimed to understand which features that lead to the construction of intolerant senses are mobilized in this act; as well as which dialogical threads are necessary for a cartoon to be considered as having intolerant contours. To this end, the article resorts to the discursive theoretical-methodological perspective, especially that postulated by the Bakhtin Circle. The analysis indicates that the cartoon in question turns to intolerant social discourses, both moving towards the already-said and projecting response-discourses. By doing so, the architectonics of cartoons assumes intolerant senses as a discursive whole in which values of judgment can be seen.

Keywords: Bakhtin Circle. Intolerant speech. Sense construction. Journalistic cartoon.

\section{Introdução}

Na contemporaneidade, por diferentes motivos, tais como embates políticos, discussões de gênero, posicionamentos ideológicos ou percepções de mundo, propagam-se tonalidades generalizantes que ancoradas em uma rede discriminatória - projetam discursos intolerantes. Pensando-se nas práticas de interação humana, sentidos dessa natureza podem estar presentes nos mais variados gêneros do discurso; neste trabalho centra-se a atenção na charge.

\footnotetext{
1 Este artigo é um recorte revisado e ampliado da tese A arquitetônica de charges com contornos intolerantes: discursos sociais em tensão, defendida em 2019. Disponivel em: http://repositorio.pucrs.br/dspace/handle/10923/15284. Acesso em: 30 out. 2019.

2 Universidade Federal da Fronteira Sul (UFFS), Chapecó, SC, Brasil.
} 
No universo daquilo que se caracteriza como charge jornalistica - ou, simplesmente, charge -, muitos sentidos são veiculados a partir de seus elementos visuais ou verbo-visuais. Assim, efeitos de humor, ironia e provocação podem ser percebidos quando é feita uma leitura sócio-historicamente situada desse gênero, entendendo-o na relação com os discursos que com ele dialogam. Por ser uma crítica, no sentido de que a charge é o discurso de um determinado sujeito sobre o mundo que lhe circunscreve (GONÇALVES, 2015, 2019), é possivel entrever pontos de vista, valorações que se constroem em sua arquitetônica, isto é, no conjunto de posicionamentos sociais, éticos e estéticos, edificado por um autor que enuncia desde um centro concreto, espacial e temporalmente.

Posicionando-se no seio dessa problemática, o olhar investigativo neste texto recai sobre o que se convencionou chamar charge com contorno intolerante (GONÇALVES, 2019). Por que contorno intolerante? Porque é possivel, a partir dos elementos verbo-visuais, em relação à dinâmica de seu contexto, identificar vozes discriminatórias ou incitatórias, que tencionam valorações sociais negativas. Essa percepção advém do entendimento de que a arquitetônica de certas charges conduz à intolerância, o que significa dizer que a depender dos elementos constitutivos da charge e dos discursos com os quais ela se relaciona pode haver contorno intolerante, isto é, uma projeção de discursos que propagam generalizações e projetam discursos sociais que circundam a intolerância.

Tendo em vista o exposto, o objetivo deste artigo é compreender os elementos constitutivos de uma charge de Roque Sponholz, veiculada em 2011, na midia digital brasileira, na relação que eles mantêm com os discursos que the antecedem e lhe sucedem. Visa-se nesse ato a entender quais recursos são mobilizados para a edificação de sentidos intolerantes; bem como se quer verificar quais fios dialógicos são necessários para que uma charge seja entendida como tendo contorno intolerante.
Em tempos de delicada tensão política, como os que se vivem atualmente, repousar o olhar sobre conteúdos temáticos que rondam justamente esse campo pode ser desafiador. Assim, analisar uma charge não tão recente, como a que neste texto se propõe, é oportuno porque ela já não convoca a emoção do momento, de modo que sua leitura não se relaciona tão diretamente com as tensões sócio-históricas quando de sua publicação, o que possibilita um olhar de distanciamento em relação ao objeto e de frieza em relação aos sentidos em jogo - especialmente no caso de charges politicas que envolvem partidos políticos e uma apreciação sobre esses. ${ }^{3}$

Para alcançar o proposto, foi selecionada para análise uma charge supostamente com contorno intolerante, a julgar por seus elementos verbovisuais - frente à tensão das vozes sociais que a atravessam na relação que conta com: o autor que a assina, o veículo em que foi publicada e no compor das tramas que se estabelecem entre os discursos contemporâneos que dialogam com ela.

Aseleção se deu em razão de se ter um exemplar de uma charge cuja construção composicionalé verbo-visual. Essa decisão permite contemplar uma parte do espectro que pode envolver os elementos de composição desse gênero. Além disso, essa eleição também considerou que, no âmbito atualidades, que é o conteúdo temático da charge, o assunto política é gerador de tensões sociais capazes de reverberar intolerância.

A preocupação com a leitura da charge é necessária porque assume, a partir da proposição teórico-metodológica em questão, uma dimensão científico-didática de valor social, uma vez que tem como compromisso ventilar ideias que possam promover o estudo desse gênero discursivo. $\mathrm{Na}$ busca pelo entendimento da arquitetônica da charge com contorno intolerante, pondera-se sobre os pressupostos necessários para sua leitura crítica, visando a contemplar, na apreciação da charge, tanto os elementos verbais quando os imagéticos, relacionando os arranjos linguísticos aos visuais, aos discursos nela tramados e por

Está-se focalizando o leitor, no sentido de engajá-lo na leitura e no intuito de que ele "escute" a análise para, sobre ela, contrapor sua palavra. 
ela projetados. Tudo em relação com o contexto social que the é constitutivo.

No que diz respeito à organização deste texto, ademais desta introdução, apresentam-se duas seções. A primeira, intitulada Teoria Dialógica do Discurso, apresenta alguns dos conceitos bakhtinianos pertinentes à análise da charge escolhida, tais como linguagem; gêneros do discurso; arquitetônica; significação; e tema. $\mathrm{Na}$ segunda seção, brevemente se discorre sobre o conceito de estereótipo, de Amossy e Pierrot (2010), a fim de que, junto às noções bakhtinianas selecionadas, leve-se a cabo o processo de análise da charge de Sponholz. Em seguida, são tecidas as considerações finais, que visam a dar o acabamento necessário a este texto, a fim de que a ele se sobreponham contrapalavras.

\section{Teoria dialógica do discurso: uma proposta para a análise de charges}

A linguística como área de estudos é ampla e está em constante renovação. Como seu escopo divide-se em diversos pontos do grande fenômeno que é a linguagem, essa ciência cresce interna e externamente, a partir da colaboração de áreas que com ela se propõem ao diálogo, como a filosofia, o direito e a sociologia, por exemplo.

A teoria dialógica do discurso ${ }^{4}$ pode ser situada internamente na linguística, seja porque essa teoria influenciou muitas das orientações de estudos no âmbito do texto e do discurso (BARROS, 2005), seja porque a linguagem é central no pensamento dos estudiosos que compõem essa teoria (TEIXEIRA, 2005). Nas palavras de Faraco (2009, p. 9), "[...] Bakhtin e seu Círculo têm já lugar consolidado na história do pensamento linguístico", pois suas discussões sobre a linguagem viabilizam entender esse fenômeno desde uma perspectiva ampla, preocupando-se em compreender as relações de sentidos, a partir de metalinguagem própria.

A teoria dialógica do discurso considera a historicidade que circunscreve os discursos sociais como fenômenos históricos, pertencentes a dinâmicas concretas, situadas em um tempo e um espaço definidos. $O$ ato de entender o discurso situado permite ver as possibilidades de sentidos que ventilam diversificadas materialidades de discursos verbais, visuais ou verbo-visuais, configurando-se frutifera para a análise de charges, por exemplo.

Além disso, a perspectiva oferecida pela teoria dialógica do discurso é oportuna porque viabiliza uma visão de língua em uso, capaz de aceitar conexões, aproximações e elucubrações de outras áreas para entender o multifacetado fenômeno que é a linguagem. Colocando-se em um enfoque de diálogo e contribuição, esse viés oportuniza olhar o discurso, seu autor, o entorno no qual tal produção de linguagem se estabelece, tudo a partir da recuperação de aspectos sócio-históricos desde uma perspectiva intersubjetiva, que permite relacionar discursos outros, saberes, crenças e valorações, necessários ao entendimento daquilo que se analisa.

Para o Círculo de Bakhtin, a linguagem se constitui pela interlocução porque toda a expressão possui uma orientação social. Assim, no entendimento desse grupo de pensadores, a interação entre os participantes de qualquer comunicação discursiva está atravessada pela situação em que se dá a comunicação, com base nos sujeitos nela envolvidos e no interesse de mover determinados temas, isto é: quem fala dirige sua palavra a alguém, mediante as especificidades de determinada situação e em referência a um assunto específico. Dessa maneira, toda a enunciação se edifica modulada pela circunstância concreta na qual se sustenta e pelo vínculo que mantém com os interlocutores partícipes dessa interação (VOLOSHINOV, 2013). ${ }^{5}$ A linguagem, nesses termos, é um fato social que deixa ver a relação de intercâmbio comunicativo sob a forma de enunciações.

Assim sendo, a linguagem em todas as suas faces participa na criação de sistemas ideológicos - isto é, sistemas de valor - como a ciência, a moral, o direito, ao mesmo tempo que constitui

\footnotetext{
Nomenclatura usada por Brait e Magalhães (2014) para se referir ao constructo teórico do Círculo de Bakhtin.

Esclarece-se que os nomes dos autores mencionados ao longo do texto seguem a grafia apresentada nas obras consultadas.
} 
a consciência de cada sujeito social que circula por esses sistemas. Por isso, Bakhtin/Voloshinov (1993, p. 242-243)6 destaca que "[...] a vida interior de todo ser está estreitamente relacionada aos meios que the servem para expressá-la. Sem linguagem interior não existe consciência, assim como não existe linguagem exterior sem linguagem interior". Em ambas as modalidades, há a orientação social, que coloca em relação os interlocutores: um falante sempre projeta a sua enunciação para um ouvinte. Ocorre que na linguagem interior o eu faz também as vezes do tu, pois mesmo no diálogo interior há um ouvinte em potencial a quem a enunciação se dirige e com base em quem ela é moldada.

A orientação social da linguagem é o que permite sua existência porque se não há enunciação não se pode "dizer" nada. Sem que haja um tu, um porquê e uma circunstância, não é possivel, com propriedade e direção, projetar o desenho do que será dito; não é possivel organizar o que se deseja dizer. O como dizer e o quê dizer dependem desses nortes. Em Bakhtin (2016), a noção de gêneros discursivos irá contemplar as limitações e os delineamentos mais ou menos estáveis dos enunciados, bem como irá demonstrar que a linguagem se organiza em certos modos de dizer que se prestam a determinadas situações de interação discursiva, com propósitos sociais específicos para os sujeitos em questão.

Essa estrutura sociológica da linguagem (BAKHTIN/VOLOSHINOV, 1993, p. 245) é o que the confere dinamicidade, uma vez que as mudanças sociais pelas quais passam os modos de interação interpessoal promovem modificações nos modos de comunicar. Em outras palavras: a linguagem se modifica conforme se move o seio social. Como na teoria dialógica do discurso a linguagem está em relação estreita com o meio social, seus elementos recorrentes têm de ser entendidos como sistemas dinâmicos. Nesse sentido é que a proposição de ver a linguagem via gêneros do discurso é uma importante contribuição dessa teoria. Desde uma perspectiva social, toda a produção discursiva de determinado grupo se dá sob gêneros discursivos mais ou menos estáveis que se modificam conforme se modifica a sociedade e suas formas de comunicar.

Há menção em outros textos, todavia, é no ensaio "Gêneros do discurso", em Estética da criação verbal, de modo mais sistemático, que Bakhtin desenvolve a noção de gêneros discursivos. De acordo com o autor (2016, p. 12), gêneros discursivos são "[...] tipos relativamente estáveis de enunciado", que apresentam conteúdo temático, estilo e construção composicional próprios, edificados com vistas a um auditório, uma orientação social e uma valoração particulares da enunciação em que se inserem. Conforme as esferas discursivas crescem e se complexificam, também os gêneros acompanham esse movimento. Dessa forma, sem colocar em dúvida a unidade nacional de uma lingua, os gêneros são heterogêneos porque a atividade humana assim o é.

Palavras surgem, outras entram em desuso, formas textuais surgem, outras se tornam obsoletas. Sentidos mudam com o tempo, renovam-se, reformulam-se. Tudo porque as práticas de interação social são modificadas em razão das circunstâncias de interação que mudam. Nesses termos, explica Bakhtin/ Voloshinov (1993, p. 246, tradução nossa) que "[...] se elaboram os mais diversos tipos de enunciações, correspondentes aos diversos tipos de intercâmbio comunicativo social".7

Nesse desenho comunicativo que contempla locutor, interlocutor, determinado assunto e um modo específico para enunciá-lo frente à situação de interação, há os sentidos que se deseja projetar. Assim, a forma de arranjo linguístico que o sujeito faz para comunicar está organizada dentro das

\footnotetext{
6 Neste artigo, não se entra na discussão acerca da autoria dos textos considerados disputados. Assim sendo, os nomes são citados conforme as referências consultadas os apresentam. No caso de Marxismo e filosofia da linguagem, por exemplo, tem-se um autor, mas a menção de dois nomes, por isso Bakhtin/Volochinov. Como a questão autoral discute se um ou outro é o autor, não acreditando em dupla autoria, os verbos são colocados no singular - a julgar pela própria apresentação do livro feita por Roman Jakobson que traz verbos no singular.

7 Do original: [...] se elaboran los más diversos tipos de enunciaciones, correspondientes a los diversos tipos de intercambio comunicativo social.
} 
possibilidades do que a língua, como um todo sistematizado e partilhado socialmente, permite - porque, conforme Bakhtin/Voloshinov (1993, p. 218, tradução nossa), "[...] existem leis linguisticas que não se pode infringir ou a compreensão reciproca torna-se impossivel". ${ }^{\circ}$

Se a sociedade vai construindo modos de dizer correspondentes às formas de intercâmbio comunicativo, os gêneros do discurso acompanham essa movimentação. Nessa dinâmica, no todo das enunciações que formam a história dos discursos que acompanham a sociedade, há valores que vão sendo fixados. Eles constituem aspectos da subjetividade de quem fala; esses valores colorem todos os discursos do ser. Assim o fazem porque foram apreendidos da nuvem flutuante dos discursos sociais na qual está circunscrito o sujeito, histórica e culturalmente. Esse repertório de enunciações - também chamadas discursos - possui significado mais ou menos estabelecido, uma vez que socialmente ocorrem usos que regulam, arbitrariamente ou não, especificações para determinados signos. Quando no discurso, envoltos pelo contexto, tais usos atualizam-se como signos ideológicos formadores de sentidos próprios das esferas em que aparecem.

Assim, ademais do significado mais ou menos estável que as construções comunicativas podem apresentar, há o sentido, aspecto da linguagem que requer o entendimento de uma determinada construção especificamente no arranjo em que foi usada, tendo a projeção daqueles parceiros comunicativos (e não de outros), sob a relação de interação desses sujeitos, em dada circunstância ocorrida em um tempo e um espaço definidos. Assim, o sentido vai dar origem a compreensões pontuais porque ele está tecido na teia da linguagem, nas relações interpessoais e nas tonalidades que uma determinada época deixa ver em determinado gênero do discurso. Desse sentido que se compõe do todo do enunciado ressoam valorações próprias da situação, das pessoas e dos modos de dizer o que se diz.

Nesse jogo, estão o que Volóchinov (2017, p. 227-238) chama de significação e tema, sendo o primeiro os elementos que se repetem, isto é, as formas regulares da língua; e o segundo o caráter inovador, isto é, a atualização que cada forma regular adquire no discurso, no uso situado e autoral. Ambas as noções são faces de um mesmo fenômeno, nascem juntas no seio dos usos. Como estão vinculadas à dinâmica social, pode ser mais evidente que o tema se apresente vivo e móvel, porém as significações são estabilizadas relativamente, pois estão sempre atreladas às formas de usos especíicos e a quadros históricos determinados. Por essa percepção, é que o olhar do pesquisador analista do discurso focaliza o gênero discursivo, haja vista que nele observa a linguagem como um fenômeno vivo e concreto.

Para fins didáticos, a explicação de significação e tema dá-se de maneira separada a fim de que se possa apreender cada noção, mas se sublinha: são constitutivas e complementares. A totalidade da enunciação como um fenômeno concreto e único, isto é, o tema, é parte integrante - junto ao significado - do sentido do enunciado. Uma unidade temática, assim como a própria enunciação, é não reiterável, uma vez que "[...] se apresenta como a expressão de uma situação histórica concreta que deu origem ao enunciado" (VOLÓCHINOV, 2017, p. 228). Tema e significação estão em relação justamente porque formas linguísticas (palavras, arranjos morfológicos e sintáticos, sons, entonações) e formas não verbais compõem o enunciado, repleto de sentidos e conteúdos ideológicos. Se o tema do enunciado é tão concreto como o instante histórico ao qual pertence, o tema é o sentido que o enunciado veicula. Isso porque o sentido é possivel apenas na totalidade da expressão do enunciado, que ocorre nos limites da concretude de um momento, na relação que equaciona gênero discursivo, sujeito, contexto, discursos anteriores e discursos projetados.

Nesses termos, tem-se a arquitetônica, essa noção bakhtiniana referente ao todo, a tudo o que compõe a situação interativa, a tudo aquilo que faz existir o evento-ato: a situação, o auditório, a teia de discursos passados e projetados. No estudo

8 Do original: [...] existen leyes lingüisticas que no pueden infringirse, o la comprensión reciproca se volverá imposible. 
de charges, a noção de arquitetônica é relevante porque deixa ver o todo discursivo, a construção ou a estruturação dos ditos, na perspectiva da organização do conteúdo frente a uma fatia de espaço e tempo. Essas instâncias formam as possibilidades de sentido. A arquitetônica é o todo: o acabamento, os limites; é base para a construção do próprio gênero do discurso (BAKHTIN, 1998). Ela implica ver a charge em sua relação com o todo sócio-histórico que lhe circunscreve. Ela é a dimensão macro que contempla e, ao mesmo tempo, compõe esse todo.

No interior do tema, do sentido do enunciado, está o reiterável e idêntico, denominado significação. São aqueles elementos fundados que respondem a uma convenção, à organização de uma dada língua. A significação é potência, é engenho, é aquilo que viabiliza a concretude do sentido. Enquanto o tema é um sistema dinâmico e complexo de signos ideológicos, moldado frente à determinada situação e projetado com base em um auditório específico, a significação é propriamente a capacidade de significar, em razão de ser ela um potencial. Não diz nem quer dizer nada por si só, haja vista ser "[...] uma possibilidade de significação dentro de um tema concreto" (VOLÓCHINOV, 2017, p. 231). Partes integrantes do enunciado, dos discursos, não há tema sem significação. Nas palavras do pensador russo:

O tema é um complexo sistema dinâmico de signos que procura se adequar ao momento concreto da formação. O tema é uma reação da consciência em constituição para a formação da existência. A significação é um artefato técnico de realização do tema. Evidentemente, é impossivel traçar um limite absoluto e mecânico entre a significação e o tema. Não há tema sem significação nem significação sem tema. [...] Por um lado, o tema deve apoiar-se em uma significação estável; caso contrário, ele perderá a sua conexão com aquilo que veio antes e que veio depois, ou seja, perderá totalmente o seu sentido (VOLOCHINOV, 2017, p. 229, grifo do autor).

Por colocar-se em relação de construção com o ser em devir, Volóchinov (2017, p. 229-230) expõe que o tema é essa totalidade de, sempre vinculada ao todo do enunciado, razão pela qual não pode ser definido apenas pelos aspectos linguístico- gramaticais, mas deve ser tomado em amplitude, pelo extraverbal mais estreitamente situacional. Entender a inter-relação entre tema e significação é parte da compreensão ativa, uma vez que:

Compreender um enunciado alheio significa orientar-se em relação a ele, encontrar o seu lugar adequado em contexto correspondente. Em cada palavra de um enunciado compreendido, acrescentamos como que uma camada de nossas palavras responsivas. Quanto maior for o seu número, quanto mais essenciais elas forem, tanto mais profunda e essencial será a compreensão (VOLÓCHINOV, 2017, p. 232).

Nessa perspectiva é que, para o Círculo de Bakhtin, compreender é apresentar uma contrapalavra à palavra do outro. Nesses termos, mais uma vez está-se frente ao caráter social da linguagem, porque quanto mais usos sociais o sujeito tiver em seu repertório de gêneros discursivos, mais contrapalavras ele opõe ao discurso do outro e, assim, mais rico discursivamente é o processo de compreensão ativa. Essa forma de compreensão amparada na linguagem como fenômeno social é dinâmica e dialógica. Dinâmica porque histórica. Dialógica porque social.

\section{Manutenção de estereótipos sociais: a charge em foco}

Nesta seção, é analisada uma charge cuja arquitetônica favorece a manutenção de estereótipos sociais negativos. Atravessados por vozes que criam uma imagem social mais ou menos estável, os estereótipos definem e limitam de antemão pessoa, coisa ou situação. Para Amossy e Pierrot (2010), em sua etimologia, a palavra estereótipo mantém relação com o termo que lhe dera procedência, uma vez que estereótipo é o trabalho feito em chapa de chumbo, que forma uma matriz capaz de originar muitas impressões, mantendo, portanto, o mesmo padrão.

Da origem das artes gráficas, surge a ideia disseminada socialmente para estereótipo como uma impressão sólida, um julgamento que se disfere sobre algo ou alguém, sobre lugar ou cultura. Essa padronagem cristalizada de julgamentos desagua, muitas vezes, em uma série de atitudes preconceituosas porque rotula ou oferece uma 
visão recortada da realidade. Amossy e Pierrot (2010) explicam que os estereótipos geralmente oferecem uma perspectiva nociva por apresentar uma fragmentação pejorativa do real à medida que generalizam e simplificam - por essência.

Socialmente, há muitos estereótipos. Vejase, por exemplo, as valorações negativas generalizantes que atravessam o universo feminino. A mulher é muitas vezes alocada em uma rede que faz com que sejam acessados discursos anteriormente produzidos e amplamente recorrentes nas mais diferentes esferas sociais: "mulheres são motivadas por suas emoções"; "mulheres são invejosas"; "mulheres competem entre si"; "mulheres preenchem seu tempo com amenidades"; "mulheres são fofoqueiras" etc. Esse movimento dialéticodialógico de discursos perpetua cristalizações, que dão origem a estereótipos, a generalizações dificeis de serem desconstruídas se não houver um entendimento crítico sobre a sociedade na qual se está inserido.

A charge a ser analisada apresenta-se empapada em discursos que deixam ver já ditos na forma de estereótipos atravessados por valorações negativas sobre o universo que registram, mas também deixam ver muito sobre a perspectiva de mundo de seu autor. Veja-se, na Figura 1, a charge, os elementos que a constituem, o ambiente que a circunscreve e, em seguida, as análises às quais se chega a partir dessa composição.

Figura 1 - Charge em análise

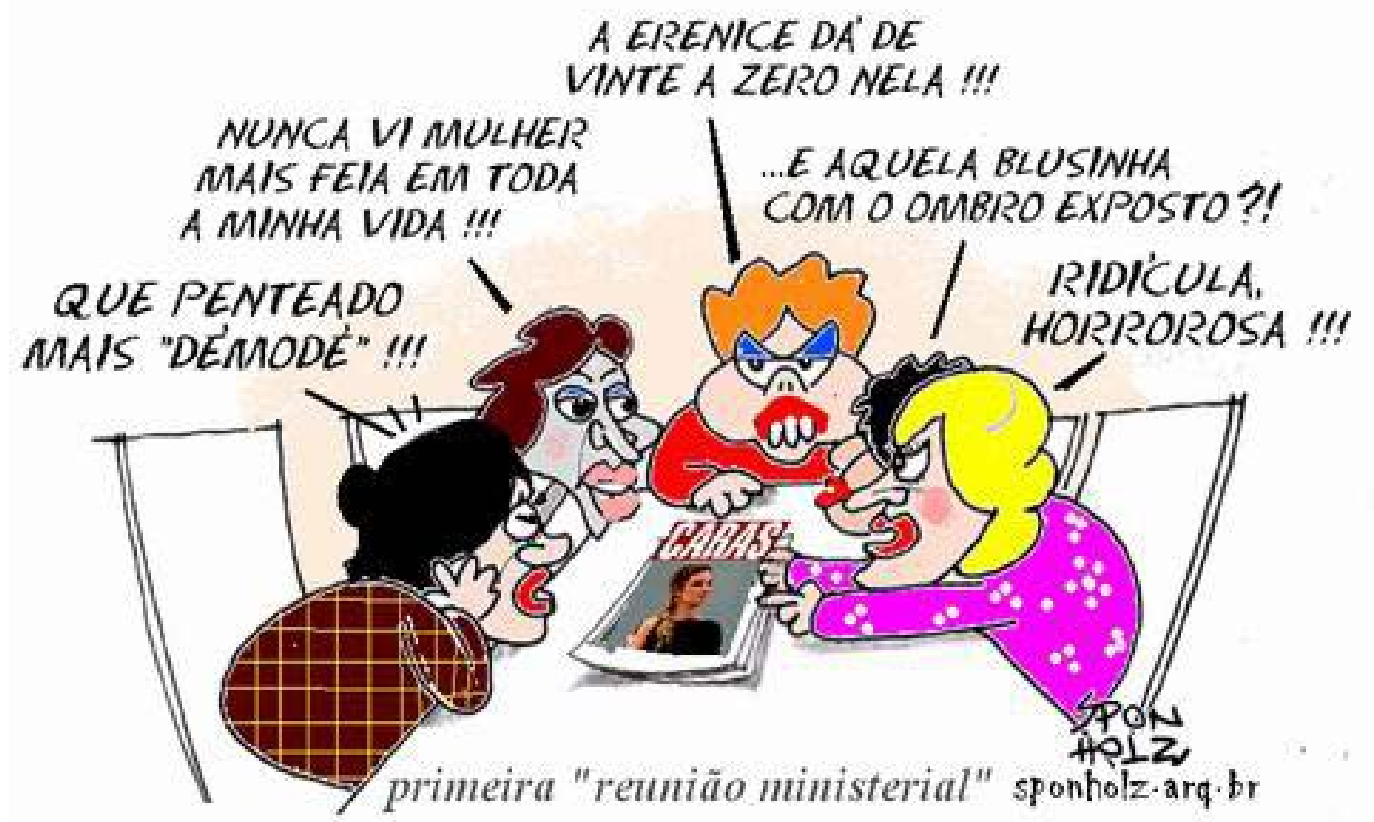

Fonte: Sponhlz (2011).

A charge focalizada, que desencadeou diferentes discursos-resposta, foi publicada em janeiro de $2011^{9}$, sendo replicada nos primeiros dias de janeiro por diferentes sites ${ }^{10}$. Assinada por

9 Disponivel em: http://sponholz.arq.br/html/index_charge_34.html. Acesso em: 19 out. 2019.

10 Sob o título "Coroas da corte", foi publicada em 4 de jan. de $2011 \mathrm{em}$ http://sergioaperon.com.br/2011/01/coroas-da-corte/. Acesso em: 19 out. 2019. "Superar estereótipos" em http://mariolobato.blogspot.com.br/2011/01/superar-estereotipos-tambem-na-imprensa. html, no dia 05 de jan. de 2001. Acesso em: 20 out. 2019. Em http://www.viomundo.com.br/blog-da-mulher/e-os-chargistas-nao-tem-nada-mais-a-fazer-do-que-piadas-sexistas.html, no dia 5 de jan., sob o título "E os chargistas não têm nada mais a fazer do que piadas sexistas?". Acesso em: 20 out. 2019. Em http://blog.tribunadonorte.com.br/abelhinha/62920, no dia 5 de jan. de 2011. Disponivel em http://www.revistaforum.com.br/mariafro/2011/01/05/superar-estereotipos-tambem-na-imprensa-e-o-primeiro-passo-para-romper-preconceitos/. Acesso em: 20 out. 2019. Há outras opiniões. "Reunião das varginas", em http://avaranda.blogspot.com.br/2011/01/reuniao-das-varginas.html, no dia 4 de jan. de 2011. Acesso em: 20 out. 2019. 
Roque Sponholz, arquiteto, cartunista, chargista e caricaturista, a charge apresenta elementos verbais e não verbais que dão forma ao discurso. Em um quadro, mostra cinco figuras femininas reunidas, conversando à mesa. Todas comentam sobre a imagem de uma figura feminina estampada na capa de uma revista de celebridades nacionalmente conhecida, a revista Caras.

A julgar pelos traços caricaturais presentes na parte não verbal da charge, trata-se da presidente eleita no final de 2010 para início de mandato em 2011 para comandar o governo brasileiro, Dilma Rousseff, e algumas de suas ministras. Essa afirmação é corroborada pela legenda que aparece centralizada na charge e diz: "primeira 'reunião ministerial'". Todas as personagens proferem comentários sobre a mulher que aparece na capa da revista. O alvo dos comentários trata-se de Marcela Temer, a esposa do vice-presidente da chapa eleita, Michel Temer. Assim, Dilma e suas ministras tecem comentários ao que seria uma fotografia de Marcela Temer na capa de uma revista.

A charge em questão foi publicada em razão da cerimônia de posse da presidente eleita, Dilma Rousseff, em 2011. Na ocasião, a mídia focalizou a presença da esposa do vice-presidente, Michel Temer, em razão de aquela ter sido uma de suas primeiras aparições oficiais. Na época, muito se falou que a presença de Marcela Temer na cerimônia foi digna de destaque por sua beleza, jovialidade e devido à sua vestimenta. Sob o mote "Marcela Temer rouba a cena", uma série de matérias foi veiculada, recupera-se mais de
67 mil resultados a partir da entrada "Marcela Temer posse Dilma 2011". Dentre eles, pode-se ler "Mulher de Temer se destaca em posse de Dilma"; Marcela Temer é assunto nos "trending topics do Twitter brasileiro e $05^{\circ}$ [assuntol mais citado no Twitter mundial" (Portal $/ G^{11}$ ); "Beleza da vice-primeira-dama rouba a cena na posse de Dilma" (O Globo'12); "Vice-primeira-dama rouba cena no Twitter" (Terra' ${ }^{13}$ ); "Ex-miss, vice-primeiradama chama atenção durante a posse" (Folha ${ }^{14}$ ); "Posse de Dilma transforma mulher de Michel Temer em musa do Twitter" (Estadão ${ }^{15}$ ).

Outra parte da mídia, sublinha-se da pequena mídia porque centrada em blogues e colunas de opinião, destacou a discrepância entre o que deveria ter sido uma cobertura de cerimônia de posse e as manchetes que abordaram muitas linhas sobre a vice-primeira-dama. Com a mesma entrada, "Mulher de Temer se destaca em posse de Dilma", dentre o total de 67 mil resultados, pode-se pinçar as seguintes manchetes: "Superar estereótipos é o primeiro passo para romper preconceitos" (BLOG DO MARIO ${ }^{16}, 2011 ;$ REVISTA FÓRUM"17, 2011); "Marcela é jovem e Bonita, e dai" (ESCREVA LOLA ESCREVA ${ }^{18}$ ); "O figurino de Dilma" (AQUELA DEBORAH"19, 2011); "Reduzir preconceito de gênero não é tarefa fácil para Dilma" (TERRA20, 2011); "Chargistas sexistas..." (PORTAL LUIS NASSIF'1, 2011).

As duas últimas publicações mencionadas, do Terra e do Portal Luis Nassif, abordam a cena da posse da presidente eleita, Dilma Rousseff, comentando-a sob a perspectiva da publicação especificamente da charge de Sponholz (Figura

\footnotetext{
11 Disponivel em: http://ultimosegundo.ig.com.br/politica/mulher-de-temer-se-destaca-em-posse-de-dilma/n1237905707801.html. Acesso em: 5 dez. 2017.

12 Disponivel em: https://oglobo.globo.com/politica/beleza-da-vice-primeira-dama-rouba-cena-na-posse-da-dilma-2844111. Acesso em: 2 dez. 2017

13 Disponivel em: https://www.terra.com.br/noticias/brasil/politica/vice-primeira-dama-rouba-a-cena-no-twitter,089897730cbda310VgnCLD200000bbcceboaRCRD.html. Acesso em: 02 dez. 2017.

14 Disponivel em: http://www1.folha.uol.com.br/poder/2011/01/853778-ex-miss-vice-primeira-dama-chama-atencao-durante-a-posse.shtml. Acesso em: 2 dez. 2017.

15 Disponivel em: http://politica.estadao.com.br/blogs/radar-politico/posse-de-dilma-transforma-mulher-de-michel-temer-em-musa-do-twitter/. Acesso em: 3 dez. 2017.

16 Disponivel em: http://mariolobato.blogspot.com.br/2011/01/superar-estereotipos-tambem-na-imprensa.html. Acesso em: 3 dez. 2017.

17 Disponivel em: http://www.revistaforum.com.br/mariafro/2011/01/05/superar-estereotipos-tambem-na-imprensa-e-o-primeiro-passo-para-romper-preconceitos/. Acesso em: 2 dez. 2017.

18 Disponivel em: http://escrevalolaescreva.blogspot.com.br/2011/01/marcela-e-jovem-e-bonita-e-dai.html. Acesso em: 2 dez. 2017.

19 Disponivel em: http://escrevalolaescreva.blogspot.com.br/2011/01/marcela-e-jovem-e-bonita-e-dai.html. Acesso em: 2 dez. 2017.

20 Disponivel em: http://www.jb.com.br/pais/noticias/2011/01/05/reduzir-preconceito-de-genero-nao-e-tarefa-facil-para-dilma/ Acesso em: 3 dez. 2017.

21 Disponivel em: http://blogln.ning.com/profiles/blogs/chargistas-sexistas. Acesso em: 3 dez. 2017.
} 
1). A partir dos elementos verbais e visuais, vê-se no discurso chargístico em questão uma cena propagada como imagem social: mulheres reunidas falando sobre algum tema.

Essa imagem toma contornos diferentes quando se soma o fato de as mulheres estarem discorrendo maldosamente sobre a foto de uma mulher que fora amplamente elogiada na mídia nacional por seus atributos físicos, conforme se pôde ver nas manchetes apresentadas. Em termos de significação, a escolha do uso do advérbio maldosamente aplica-se em razão das falas com alto teor de adjetivação, que conferem atmosfera pejorativa ao referente da apreciação, fotografia de Marcela Temer na capa da Caras, tal como se pode ler nas entradas de fala de cada personagem da charge: 1) "Que penteado mais 'démodé'!!!"; 2) "Nunca vi mulher mais feia em toda a minha vida!!!"; 3) "A Erenice dá de vinte a zero!!!"; 4)“... E aquela blusinha com o ombro exposto?!"; 5) "Ridicula, horrorosa!!!".

Cada fala é um enunciado carregado de valorações sociais negativas porque suscita os discursos anteriores que envolvem a situação de posse da presidente eleita e os estereótipos de gênero. Essa rede de já ditos projeta sentidos no conteúdo da cena que foi retratada na charge. A valoração negativa na arquitetônica da charge vai se especificando quando se repousa o olhar sobre os adjetivos. Na relação do todo enunciativo em que aparecem, essas palavras constroem conteúdos subjetivos baseados em imagens sociais: em 1) "Que penteado mais 'démodé'" e 4) "... E aquela blusinha com o ombro exposto?!", tem-se uma avaliação comportamental a partir do modo de se apresentar: o cabelo e a vestimenta. Em 2) "Nunca vi mulher mais feia em toda a minha vida!!!" e 3) "A Erenice dá de vinte a zero!!!", tem-se um julgamento da aparência física via comparação interpessoal.

Especificamente, em 3) "A Erenice dá de vinte a zero!!!", pode-se realizar mais duas leituras. A primeira seria uma relação de pertencimento e não pertencimento de grupo, já que no enunciado "A Erenice dá de vinte a zero!!!" é axiologicamente valorada a percepção nós contra eles, construindo valorações positivas para aqueles pertencentes ao mesmo grupo e negativas para os não pertencentes. Assim, esse discurso deixa ver na relação dialógica entre a cena da charge e o contexto sócio-histórico de sua composição que Erenice é "melhor" porque pertence ao nós, ao mesmo grupo de quem profere o discurso, podendo construir sentidos de apoio coral entre os membros do mesmo partido, o Partido dos Trabalhadores (PT). Isso leva à segunda questão em torno desse discurso, a saber, a avaliação pessoal acerca de valores morais, uma vez que o nome Erenice aponta para a relação entre a presidente Dilma Rousseff e Erenice Guerra, advogada filiada ao PT, considerada pela mídia como braço direito de Dilma. Muitas vezes, foi noticiada ${ }^{22}$ a aproximação entre essas duas figuras públicas.

A peculiaridade da escolha do nome Erenice na fala da personagem com traços caricaturais da pessoa pública Dilma Rousseff agrega à charge uma valoração pontual porque Erenice Guerra esteve envolvida em denúncias ${ }^{23}$ de corrupção, o que, na charge, pode estar sendo focalizado via extensão, isto é, como a presidente tece elogio nomeadamente, destaca predicados da nomeada - Erenice. Por outro lado, ao tecer comentário favorável nomeadamente, Dilma mostra-se em consonância com a pessoa nomeada. Se duas pessoas são afins, pode ser que se julgue uma pelo comportamento da outra, como em uma tentativa de trazer à tona o ditado corrente em português que diz "diga-me com quem andas que te direi quem és", suscitando nesse ato toda a entoação valorativa que essa expressão na lingua pode edificar como projeções de sentidos.

Em 5) "Ridicula, horrorosa!!!", pode-se entender uma valoração de escárnio gratuito, porque

\footnotetext{
22 "Erenice braço direito de Dilma", disponivel em: https://veja.abril.com.br/blog/reinaldo/erenice-ex-braco-direito-de-dilma-demitida-por-causa-de-lambancas-da-casa-civil-esta-de-volta-e-continua-poderosa-ninguem-vaia-ninguem-protesta-ninguem-da-selinho-8230//: "O esquema Erenice", disponivel em: https://istoe.com.br/448524_O+ESQUEMA+ERENICE/; "Dilma e Erenice sempre juntas", disponivel em http://www.psdb.org.br/acompanhe/noticias/ex-ministra-da-casa-civil-no-governo-dilma-recebeu-r-25-mi-na-lava-jato/attachment/erenice-guerra-ex-ministra-da-casa-civil-e-dilma-foto-ebc/. Acesso em: 5 de jan. 2018.

23 Disponivel em: http://istoe.com.br/erenice-confirma-governo-lula-favoreceu-empreiteiras-em-belo-monte/; http://epoca.globo. com/politica/expresso/noticia/2017/05/erenice-guerra-fecha-escritorio-de-advocacia.html. Acesso em: 5 jan. 2018.
} 
quando não há argumentos, geralmente, o que se tecem são comentários sobre a pessoa-alvo da apreciação. Socialmente, comentários dessa natureza podem também reverberar imaturidade, justamente pelo seu esvaziamento em termos de conteúdo. Essa valoração pode deixar ver mais sobre quem a produz do que sobre a quem está direcionada sua crítica. Assim, o discurso expressado em "Ridícula, horrorosa!!!" aporta à arquitetônica da charge um ambiente hilário, de zombaria, que se volta para as personagens da "reunião ministerial", e não para o que a personagem loira de rosa diz - note-se que o traço infantil do discurso dessa personagem é corroborado por sua roupa e por sua maquiagem, já que o tom de rosa por ela usado é socialmente entendido como uma cor infantil; e a maquiagem tosca também remete socialmente a uma imagem de maquiagem feita por crianças em brincadeiras, cujo foco seja a pintura no rosto.

O que os enunciados das personagens da charge podem reverberar? Inicialmente, podese explorar a questão social de que mulheres costumam observar avaliativamente outras mulheres. De modo geral, essa valoração social dá-se negativamente quando o objeto da apreciação é visto como concorrente. Nesses termos, ocorre uma espécie de depreciação para a autopromoção do grupo que avalia o concorrente. Nesses casos, desprezo dos atributos físicos, comparação, desprestígio e escárnio imotivado tendem a gerar um efeito catártico: ao tomar o outro como insignificante, a partir de valoração explicitamente negativa, o eu ganha contornos superiores. Na charge: o grupo de Dilma desqualifica a vice-primeiradama para engrandecer-se. Pode-se ver nesse ato uma valoração de soberbia, desencadeada a partir do efeito de sentido humor.

Essa relação deixa também ver tensionamento projetado no contraste superioridade/ inferioridade. Isso tanto no que diz respeito aos personagens da charge (a presidente e as ministras em relação a Marcela Temer) quanto em relação ao chargista e o alvo de sua crítica, isto é, de sua apreciação: a cena da primeira reunião de Dilma com suas ministras.

A primeira situação é dada na relação presença/ ausência e grupo interno/grupo externo. Dilma e as ministras mostram comportamento de adesão, estão unidas no propósito de ridicularizar Marcela, de questionar sua postura, seus atributos. Estão, pois, reunidas para enquadrar Marcela em uma perspectiva daquilo que é contrário ao que elas acham certo, por isso as integrantes do grupo interno são melhores que a fonte do alvo: elas são superiores e tentam rebaixar Marcela, que configura o grupo externo.

O chargista, por sua vez, como autor, tem o poder de construir seu discurso com base em seu universo de valores, focalizando um ponto de vista, o seu. Nesses termos, ele é o "dono" do traço, ele é o espectador em posição superior, ele assume uma atitude responsiva de quem é capaz de ver além: de sua eminência criadora, ele é superior para emitir o juizo de valor que quiser, tanto que em sua construção ridiculariza a presidente e suas ministras - claro, isso do ponto de vista da arquitetônica que ele como autorcriador origina e da qual faz parte; os sentidos que se edificam pelos compreendedores são outros, podendo estar associados ou dissociados do projeto de dizer do chargista.

Assim, pode-se ver nesse ato um autor-criador que ironiza e debocha com essa relação, já que ele próprio cria uma arquitetônica do ridículo quando acresce à charge a legenda "primeira 'reunião ministerial"', cuja parte reunião ministerial aparece entre aspas, um recurso de pontuação usado para dar tom irônico ao que se fala, para minimizar o potencial de sentido do que está escrito, mas elevar aquele que fica subentendido, assinalando que se quer dizer o contrário do que se diz.

Assim, as camadas de sentido que podem ser projetadas são: em um primeiro momento, 1) a arquitetônica da charge ridiculariza Marcela Temer e, em uma segunda leitura, 2) a charge em sua arquitetônica ridiculariza Dilma e suas ministras.

Isso porque a primeira leitura se dá com base nos elementos aparentes da charge. Já a segunda leitura vai ter por base a arquitetônica desse discurso, contando com a imagem do 
autor e com o veículo de publicação. O autor da charge, que também é o autor do site em que a charge foi veiculada, Sponholz, autodescreve-se como quem luta pela política com "P" maiúsculo, independentemente de mandato ou não. ${ }^{24}$ Ele se descreve, ainda, como crítico ríspido do Partido dos Trabalhadores (PT) 25 - justamente ao qual Dilma Rousseff é filiada.

Em entrevista ${ }^{26}$, Sponholz declarou que o expresidente Lula da Silva era "PresiMente" e que Dilma Rousseff era "uma paranóia", ao passo que Fernando Henrique Cardoso (do PSD, partido axiologicamente inverso à proposta do PT) seria um exemplo de verdadeiro presidente. Quando questionado sobre o significado da palavra política, mencionou "ética", fazendo tensionar sua imagem de real presidente ( $\mathrm{FHC}$ ) ao conceito de ética e tudo o que ele reverbera. Quando perguntado sobre qual seria a sua referência de cartunista, respondeu "Lula, que pinta e borda com a cara dos brasileiros". Com base nessas informações, vê-se que Sponholz possui uma imagem de autor altamente vinculada à crítica do PT. Sua identidade discursiva deixa ver essa valoração e sua imagem social lhe é outorgada como "crítico ríspido"27 do PT. Então, tanto ele se projeta como militante contrário ao PT em suas obras (identidade discursiva), quanto the é concedida essa responsabilidade socialmente (identidade social).

Retornando à análise dos elementos da charge, vê-se que os enunciados estão acompanhados de pontuação expressiva, reforçando o seu conteúdosentido e deixando em alarde duas entoações valorativas: a do enunciado em si, atribuida aos personagens, e a do autor-criador, responsável pela veiculação do sentido que se projeta. Três dos quatro comentários possuem ponto de exclamação, o que reforça a adjetivação do conteúdo focalizado, elevando o tom daquilo que é enunciado verbalmente na modalidade escrita.

A altissonância aplicada à exaltação do enunciado é ampliada na ênfase que o emprego triplo do ponto de exclamação dá ao que é exclamado, caracterizando intensidade tonal do sentido entreouvido no exposto para além daquela que um ponto de exclamação por si só faria. O enunciado que apresenta a combinação de um ponto de interrogação seguido de um ponto de exclamação representa surpresa acentuada, como aquela característica de quem pergunta e responde ao mesmo tempo, como se questionasse retoricamente sobre algo. A combinação dessa pontuação discursivamente dá ao enunciado ares de descrença (como em enunciados do tipo: "é inacreditável que alguém use tal roupa em uma cerimônia daquelas").

A observância dos elementos linguísticos é oportuna porque ela mostra que os elementos reiteráveis também são convertidos em sentido quando se analisa o todo do enunciado na emergência do contexto histórico. Assim, dizse que os arranjos verbais construidos na charge são escolhas "[...] não determinadas pela gramática, mas por considerações puramente estilisticas, isto é, pela eficácia representacional e expressiva dessas formas" (BAKHTIN, 2013. p. 25). Os elementos verbais e não verbais são arranjados no discurso com um projeto de dizer, a partir do desejo de deixar ver certo sentido, de modo a atingir (quando se pretende ferir), alcançar (quando se quer fazer chegar) um tu especifico.

Essa arquitetônica é de ataque, em primeiro lugar, à figura da presidente eleita, Dilma Rousseff e, em segundo lugar, às mulheres de modo geral já que o ataque é edificado com base em um estereótipo de gênero. O sentido (tema) dessa interpretação é tão concreto como a temporalidade dessa charge como discurso circunscrito a um tempo e a um espaço. A significação se integra ao tema, formando com ele um todo valorativo a partir do qual podem ser vistas as entoações expressivas na arquitetônica de toda a charge.

Apresentar as mulheres da forma como foram ilustradas acentua a avaliação que deixam ver o tema e a significação. Elas estão caricaturadas, isto é, na retratação das personagens da charge

24 Disponivel em: http://www.tribunadainternet.com.br/autorretrato-de-sponholz/. Acesso em: 3 jun. 2018

25 Disponivel em: http://ucho.info/200g/07/07/a-cara-de-quem-pinta-o-brasil/. Acesso em: 3 jun. 2018.

26 Disponivel em: http://ucho.info/2009/07/07/a-cara-de-quem-pinta-o-brasil/ Acesso em: 4 jun. 2018.

7 Disponivel em: http://ucho.info/2009/07/07/a-cara-de-quem-pinta-o-brasil/. Acesso em: 2 jun. 2018. 
foi empregado o recurso da linguagem gráfica que potencializa caracteristicas físicas a fim de formar um retrato ridiculo ou exagerado para desqualificar. Esse retrato caricato da presidente e suas ministras se contrapõe à representação de Manuela Temer, que aparece em uma fotografía. Além da diferença de registro - uma caricatura e outra uma exposição luminosa que eterniza um dado momento na fixidez do registro fotográfico, essa imagem ainda estampa a capa de uma revista de distribuição nacional. Nesse jogo é construída uma avaliação que ventila a apreciação que enuncia: pessoas bonitas saem em capas de revistas e pessoas feias as invejam. Isso eleva Marcela Temer e ridiculariza a presidente e suas ministras.

A oposição fotografia versus caricatura também é significativa porque são propostas diferentes de apresentação. Ambas dependem do olhar de seu autor, mas, de modo geral, socialmente se entende que a primeira registra a beleza tal como o reflexo que se vê no momento enunciativo; a segunda deforma, destaca algum desagrado, apresenta traços hiperbolizados.

Esse contraste se soma às vestimentas das personagens. Marcela Temer aparece elegante e bem vestida na fotografia, como o estava na cerimônia de posse, uma ocasião formal que requer o cumprimento de determinada norma social, portanto uma situação em que há de se atuar conforme seria um padrão socialmente esperado para tal ocasião. Já a presidente e as ministras estão reforçando a avaliação negativa que reverbera o linguístico: uma veste roupa xadrez, em referência visual à estética do que é antigo, démodé, fora de moda; a mesma personagem usa um coque baixo, tal como é próprio de pessoas mais velhas (outra referência social para antigo e fora de moda); a que enuncia "ridícula, horrorosa!!!" está vestida de rosa, cor socialmente valorada como uma caracteristica infantil (além de ser uma cor relacionada à mulher), cuja estampa da blusa a infantiliza ainda mais; sua maquiagem é grotesca, apresenta blush em círculo bem marcado nas maçãs do rosto, característico da maquiagem de palhaços ou de crianças que brincam de se pintar. Dilma é representada de vermelho, uma menção ao Partido dos Trabalhadores, talvez dai sua fala evocar Erenice, companheira de partido - notese que essa relação dialógica com o PT assume traço importante na charge porque reverbera intenção de atingir o grupo. Além disso, Dilma é representada como dentuça, de modo a desqualificá-la, em uma forma de ataque pessoal a partir das caracteristicas fisicas aumentadas, distorcidas ou hiperbolizadas de uma pessoa.

Os elementos reiteráveis, que formam a significação, não são imposições como se a lingua fosse uma espécie de instituição. Caso se tome por base a teoria dialógica do discurso, as significações são um conjunto de construções sociais relativamente estabilizadas a partir dos diversos usos.

Essa relativa estabilidade se dá em razão da flutuação social que atualiza a lingua - sublinhase o fato de que as significações são estabilizadas, mas não fixas em termos absolutos e irredutiveis, haja vista que ao longo do tempo vão se somando traços de significação às palavras, isto é, pelos usos, as significações ganham mais potência: uma mesma palavra, por exemplo, pode projetar diferentes possibilidades de significação porque historicamente ela acumulou esses traços.

A maneira de representação das formas estáveis deu-se socialmente, ao longo do tempo, em que, por exemplo, o adjetivo ridicula - presente no enunciado 5 - possibilita fazer uma apreciação valorativa pejorativa de alguém, que se sabe mulher pela marcação de gênero: o morfema -a. Por que pejorativa? Porque o uso do adjetivo em questão tomou contornos como digna de riso, de escárnio, de insignificância. Conforme Volóchinov (2017, p. 106-107), as palavras são como indicadores sensiveis das mudanças sociais, haja vista que elas são capazes de fixar as fases transitórias das mudanças sociais. As palavras, comenta o autor, são capazes de lentas acumulações quantitativas, uma vez que fixam as fases "transitórias das mudanças sociais, por mais delicadas e passageiras que elas sejam".

Tomando o dizer do autor russo, entende-se que, a partir de enunciados outros, vão sendo fixados socialmente no sistema linguistico de 
uma determinada comunidade certos significados que, na aplicação de um contexto específico, sob a inclinação de um autor que se dirige responsivamente a um parceiro da comunicação discursiva, tecem-se sentidos. Esses sentidos, por sua vez, podem pela recorrência do uso levar à fixação de mais traços de significação à determinada palavra. Assim, por exemplo, a partir dos usos sociais que foram feitos da palavra ridicula, ela possui suas possibilidades de significar. Ela existe virtualmente na lingua portuguesa com essa potência de significado: risivel, insignificante, digna de desprezo e desdém, entre outros.

Uma vez que há significados mais ou menos estáveis no registro do sistema, quando arranjada em um enunciado, partícipe de um todo, em relação na cadeia da comunicação discursiva, eis o tema, esse sentido "[...] atributo apenas da enunciação completa" (VOLÓCHINOV, 2017, p. 227). Isso implica pensar em tudo o que a palavra ridicula ressoa em termos de sentido quando olhada especificamente naquela charge em que foi arranjada, no contexto dos aspectos verbo-visuais em que aparece, meio à situação histórico-social em que figura, sob a assinatura de determinado sujeito concreto e único, desde o lugar em que ocupa como ser em relação com o mundo, frente aos possiveis parceiros da comunicação discursiva aos quais esse autor se dirige e na arquitetônica de um autor-criador específico. Nesses termos, mais do que um significado e um tema, toda palavra entoada também deixa ver uma avaliação (VOLÓCHINOV, 2017, p. 233).

O sentido da totalidade do enunciado é uma composição complexa, advinda de elementos repetiveis e não repetíveis, isto é, recorrentes no sistema linguístico, e novos porque contextuais. Assim, o "[...] tema do enunciado é definido não apenas pelas formas linguísticas que o constituem - palavras, formas morfológicas e sintáticas, sons e entonação -, mas também pelos aspectos extraverbais". Volóchinov (2017, p. 229) expõe que o tema é essa totalidade de, sempre vinculada ao todo do enunciado. Justamente por essa razão não pode ser definido apenas pelos aspectos linguístico-gramaticais, mas pelo extraverbal mais estreitamente situacional. Nessa perspectiva, "[...] todo o enunciado é tão concreto quanto o momento histórico ao qual ele pertence" (VOLÓCHINOV, 2017, p. 230). Histórico em uma dimensão microscópica, haja vista a concretude do ato enunciativo e dos sujeitos concretos e únicos que o enunciam.

Quando tema, pode-se ver já não mais virtualidade, senão um signo ideológico porque carregado axiologicamente, tanto pelas valorações que deixam ver especificamente aquela forma escolhida [(5) ridícula], no sentido de que já houve um movimento de escolha para encontrar uma forma de dizer o que se quer dizer. Outra questão é que o tema já equaciona os acentos de valor oriundos do arranjo verbal e não verbal, os aspectos reiteráveis e não reiteráveis, haja vista o ato concreto no qual se desenvolve a enunciação, via tomada de uma atitude responsiva de sujeitos social e historicamente situados, agindo dialogicamente no mundo em que estão circunscritos.

Em Questões de estilistica no ensino de língua (1940), Bakhtin aborda a importância de atentar para os recursos gramaticais desde que esses sejam entendidos meio ao contexto do enunciado em que aparecem. Ademais, atenta para a análise dos sentidos possiveis que cada construção compõe, haja vista que dela ecoam certos efeitos de sentido. Nas palavras do autor, "[...] as formas gramaticais não podem ser estudadas sem que se leve em conta seu significado estilístico" (BAKHTIN, 2013, p. 23). Essa compreensão dos aspectos sistemáticos da língua tem de ocorrer no entendimento do arranjo em que os elementos gramaticais figuram, a fim de que seja possivel perceber o caráter axiológico tecido na composição, em razão de que "[...] toda forma gramatical é, ao mesmo tempo, um meio de representação". Esse entendimento requer que ela seja analisada desde "[...] o ponto de vista das suas possibilidades de representação e de expressão" (BAKHTIN, 2013, p. 24).

Frente ao contexto da charge de Sponholz, poder-se-ia questionar: essa imagem é real? 
Que tipo de vozes sociais ela ressoa? Por que as mulheres são assim retratadas socialmente? Por que especificamente Dilma Rousseff e as quatro ministras estão sendo assim retratadas em uma charge logo depois da posse? Quais as vozes sociais atravessam a relação entre um grupo de mulheres falando mal de outra mulher e o cargo que essas representam? Qual a critica amarrada na tessitura desses elementos?

Como qualquer discurso é uma crítica, no sentido de ser uma apreciação, o juízo de valor sobre determinado fato, há a possibilidade de se apreendê-lo de duas maneiras. A primeira é observá-lo como um discurso que reverbera uma cena cotidiana de mulheres reunidas, discorrendo sobre um determinado assunto. Essa leitura já teria alguns problemas em razão de apresentar uma imagem social de mulheres reunidas para maldizer outra mulher, fazendo, assim, ventilar um estereótipo social que existe - porque se identificam vozes na sociedade que reverberam esse tipo de valoração -, mas que por razões advindas das problemáticas que qualquer estereótipo impõe não devem ser cristalizadas: estereótipos são imagens generalizantes, distorcidas, rasas e com algum grau de preconceito. A segunda possibilidade é entender a charge apresentada como um recurso político. Nessa linha, ao que se disse sobre a charge promover a manutenção de um estereótipo social, acrescentar-se-ia o fato de ela ser tecida sobre uma argumentação falha, ad hominem, em que se atacam pessoas e não argumentos. A charge ataca Dilma e as ministras pelo fato de serem mulheres; não há argumentos em pauta.

A manutenção de estereótipos sociais na charge faz emergir o baixo nivel argumentativo dos debates políticos. Por meio de estereótipos de gênero, o autor promove uma generalização pejorativa de que mulheres, ainda que ocupem cargos de elevada responsabilidade, somente discorrem sobre temas irrelevantes, como é o caso de comentar amenidades de uma revista de entretenimento. Além disso, o projeto da charge deixa ver que as mulheres se definem por uma imagem social de maldizer outras mulheres, suas concorrentes, em um ato de manifestação invejosa contra mulheres mais jovens ou mais idealmente alinhadas com os padrões de beleza de cada tempo. Esse padrão de beleza ligado à jovialidade é imposto socialmente e reforçado na arquitetônica da charge, via estereótipos e pré-discursos, pré-construidos, suscitados pela totalidade do discurso dessa charge.

Essa caracterização pejorativa do ser mulher pode dar vazão a discursos machistas ou intolerantes por parte daqueles que não são partidários da presidente eleita naquela situação quando da veiculação da charge. Nesses termos, a arquitetônica da charge, ao tecer crítica insiste-se: fazer um julgamento de valor sobre um fato social - sobre Dilma e suas ministras pode fazer emergir atitudes intolerantes como o são o machismo e as questões pejorativas advindas dos estereótipos de gênero. Alguns podem apontar que o traço humorístico da charge desvirtua conclusões mais sérias. Outros podem dizer que não deve haver espaço para a promoção de discursos que ecoem ou possam ecoar intolerância em quaisquer situações. Neste artigo, está-se de acordo com a última colocação.

Por todo o exposto, a charge mostra-se com um projeto enunciativo que delineia intolerância, a julgar sua arquitetônica que reverbera tensão entre os elementos verbo-visuais e as vozes sociais que a atravessam. Então, o que se tem é uma charge de contorno intolerante em que, ao dar luz às críticas em relação ao governo de Dilma, o autor da charge o faz via estereótipos sociais, dando a oportunidade de que se construa a imagem de que Dilma não executa bem sua função porque é mulher. Essa interpretação engrossa o caldo dos clichês e estereótipos sociais, não contribuindo com os movimentos de igualdade e equidade deste século.

É importante sublinhar que isso se afirma em relação à charge analisada, em que o chargista baseia sua crítica política em estereótipos femininos. Porém, esse contorno intolerante é visto na charge que foi analisada, não na obra do artista como um todo. Isso porque, em uma busca pelo perfil do autor, o que se vê são críticas direcionadas a Dilma porque ela é de 
um partido político que não tem a anuência do autor. Essa valoração de Sponholz para com Dilma é recorrente em sua obra, sempre a desqualificando, diminuindo em relação às suas atitudes políticas. Tal como se pode ver na Figura 2, que compila outras charges do autor.

Figura 2 - Dilma nas charges de Sponholz
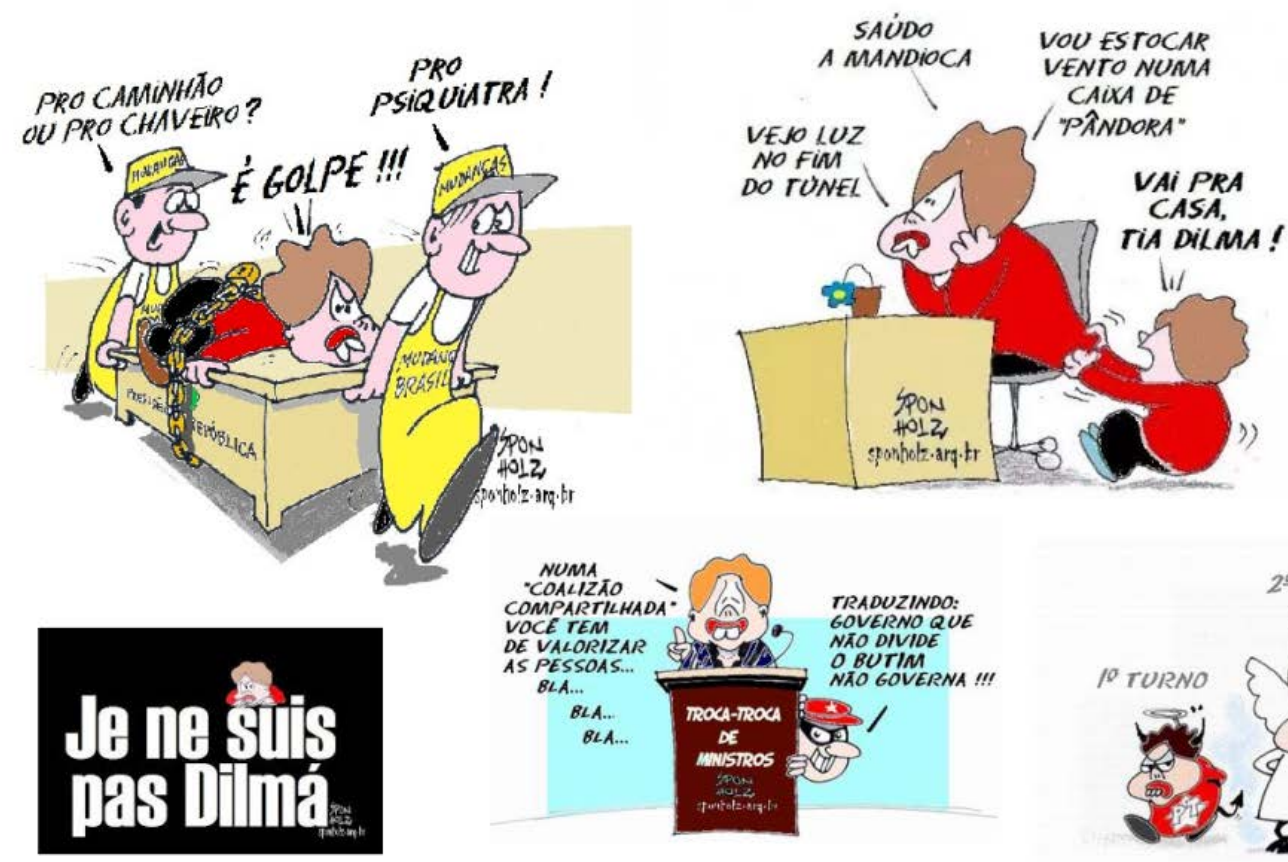

Fonte: Compilado pela autora a partir de imagens da internet.

\section{Considerações finais}

A charge analisada edifica-se em torno de um assunto polêmico: política. Isso porque sabidamente ele reverbera discursos tensos, pois é gerador de embates sociais históricos. Há, portanto, juízos de valor que balizam a relação de alteridade entre o eu e o tu, sobretudo a partir das imagens que cada um cria na dinâmica do eu-para-o-outro e do outro-para-mim.

As tensões também existem porque é comum que cada participante da interação discursiva assuma o seu centro de valor como juizo unicamente válido, entrando em ruptura com o outro. Nos casos extremos, passa a criar uma discrepância tão grande, que podem ser manifestados posicionamentos intolerantes, que se deixam ver nas entrelinhas do discurso.

A intolerância se revelou pela via do escárnio, desenvolvendo-se por meio da ironia e do sarcasmo, no caso da charge analisada. Nela, o autor-criador construiu uma arquitetônica do ridículo, de modo a expressar uma valoração de desaprovação frente aos fatos que eram refletidos e refratados na charge construída.

Assim, o contorno intolerante dessa charge não está na manifestação política em si, mas na maneira como ela é explicitada, via estereotipização e via ataques de gênero. Nesses termos, o discurso analisado é considerado uma charge com contorno intolerante porque seus elementos constitutivos se direcionam para já ditos intolerantes, bem como edificam discursos-resposta que projetam intolerância. No tensionamento da charge com o todo histórico e social, sua arquitetônica conduz à intolerância porque reverbera sentidos dessa natureza.

Isso posto, neste artigo, ao centrar a atenção sobre o gênero charge, foi possivel, a partir do aporte teórico-metodológico do discurso, entender como se constituem os sentidos quando se está pautado em uma perspectiva 
de linguagem em uso. Nesses termos, o desejo é de que este texto possa ventilar uma proposição de trabalho com o gênero charge, mais especificamente o que se chama de charge com contorno intolerante (GONÇALVES, 2019).

As discussões arroladas permitem que se reflita sobre o gênero em questão, mas também sobre leitura e compreensão de discursos verbo-visuais de modo geral, viabilizando, por exemplo, o que é preconizado pelos documentos oficiais, tais como é o caso da Base Nacional Comum Curricular (2018), em que há clara menção ao fato de que o ensino de Língua Portuguesa precisa propor uma dinâmica em que os elementos da língua sejam vistos como edificadores dos gêneros em que aparecem, de modo que seja entendida a escolha em razão do uso. A linguagem deve ser trabalhada a partir do uso, materializado em diferentes gêneros.

Trabalhar com uma perspectiva de linguagem em uso é entendê-la como forma de interação, mobilizando sentidos que se dão em contextos sociais e históricos determinados, frente a sujeitos também sociais e históricos. Isso significa olhar os usos na explosão das questões sociais que eles engendram e entender como os sentidos se formam na tensão entre significação e tema, uso e contexto, língua e sociedade.

No caso da charge analisada, a partir de sua arquitetônica, puderam-se abordar questões de gênero, política, discurso midiático; produção e recepção de gêneros discursivos; leituras; identificação de pontos de vista; e argumentação. Nesse exercicio, foi possivel manifestar que ler charges - da maneira que aqui se fez - é analisar possibilidades de sentidos advindas da relação autor/obra/leitor.

\section{Referências}

AMOSSY, Ruth; HERSCHBERG-PIERROT, Anne. Estereotipos y clichés. Buenos Aires: Eudeba, 2010.

BRASIL. Ministério da Educação. Base Nacional Comum Curricular (2018). Disponivel em: http://basenacionalcomum.mec.gov.br/. Acesso em: fev. 2020.

BAJTÍN, M; VOLOSHINOV, V. ¿Qué es el linguaje? In: SILVESTRI, A; BLANCK, G. Bajtin y Vigoski: la organización de la enunciación. Barcelona: Antropos, 1993.
BARROS, Diana Luz Pessoa de. Contribuições de Bakhtin às teorias do discurso. In: BRAIT, Beth (org.) Bakhtin: dialogismo e construção de sentido. 2. ed. Campinas: UNICAMP, 2005.

BAKHTIN, M. Os gêneros do discurso [1979]. Trad. Paulo Bezerra. São Paulo: Martins Fontes, 2016c

BRAIT, Beth; MAGALHÃES, Anderson Salvaterra (org.). Dialogismo: teoria e(m) prática. São Paulo: Terracota, 2014

FARACO, Carlos Alberto. Linguagem e diálogo: as ideias linguísticas do Círculo de Bakhtin. São Paulo: Parábola, 2009.

GONÇALVES, Tamiris Machado. Vozes sociais em confronto: sentidos polêmicos construídos discursivamente na produção e recepção de charges. 2015 Dissertação (mestrado em Letras) - Pontificia Universidade Católica do Rio Grande do Sul. Porto Alegre, 2015. Disponivel em: http://repositorio.pucrs.br/ dspace/bitstream/10923/7160/1/000466609-Texto\%2bCompleto-0.pdf.

GONÇALVES, Tamiris Machado. A arquitetônica de charges com contornos intolerantes: discursos sociais em tensão. 2019. Tese (Doutorado) - Pontifícia Universidade Católica do Rio Grande do Sul. Porto Alegre, 2019. Disponivel em: http://repositorio.pucrs. br/dspace/handle/10923/15284

TEIXEIRA, Marlene. O Círculo de Bakhtin e a lingüistica: o abstrato e o concreto na constituição do sentido. Revista Desenredo, v. 1, n. 2, 2009. Disponivel em: http://seer.upf.br/index.php/rd/article/view/489. Acesso em: jan. 2018.

VOLÓCHINOV, V. A construção da enunciação (1930). In: A construção da Enunciação e outros ensaios. São Carlos: Pedro \& João, 2013.

VOLÓCHINOV, V. Marxismo e Filosofia da linguagem: Problemas fundamentais do método sociológico na ciência da linguagem (1929). Trad. Sheila Grillo e Ekaterina Vólkova Américo. São Paulo: 37, 2017.

\section{Tamiris Machado Gonçalves}

Pós-doutorado em Estudos Linguísticos pela Universidade Federal da Fronteira Sul (UFFS), onde é bolsista PNPD/CAPES vinculada ao projeto de pesquisa "Ser-estar-entre-línguas-culturas: lingua, identidade e formação de professores". Doutora e Mestra em Letras pela PUCRS.

\section{Endereço para correspondência}

Tamiris Machado Gonçalves

Universidade Federal da Fronteira Sul

Rodovia SC 484, Km 02, Bloco A, sala 404

89815-899

Chapecó, SC, Brasil 